\title{
Chemerin promotes the development of diabetic retinopathy
}

\author{
Mengyi Liu ${ }^{1}$, Xiaoye Wang ${ }^{2}$ and Junhui $\mathrm{Du}^{3 *}$ \\ ${ }^{1}$ Department of Clinical medicine, Yan'an University, Shengli road 580, Yan 'an, 716000, Shaanxi Province, China \\ ${ }^{2}$ Department of internal medicine, Xi'an Ninth Hospital Affiliated to Medical College of Xi'an Jiaotong University, Xi'an 710054, Shaanxi Province, China \\ ${ }^{3}$ Department of Ophthalmology, Xi'an Ninth Hospital Affiliated to Medical College of Xi'an Jiaotong University, Xi'an 710054, Shaanxi Province, China
}

\begin{abstract}
Diabetic retinopathy is a serious eye disease that leads to blindness, and its development is related to inflammation, oxidative damage, and various pro-angiogenic cytokines. Studies in recent years have found that chemerin plays an important role in the development of DR. And the chemerin is also involved in the formation of retinal neovascularization. Therefore, in this article, we expound the relationship between chemerin and DR and its role in the formation of RNV.
\end{abstract}

\section{Introduction}

Diabetic Retinopathy (DR), a serious ocular complication caused by diabetes, is an important cause of blindness in the working population. The development of DR is closely related to oxidative damage, inflammation and various pro-angiogenic cytokines [1]. The formation of Retinal Neovascularization (RNV) is the main pathological change of proliferative diabetic retinopathy (PDR). In recent years, studies have found that Chemerin plays an important role in the development of DR [2,3]. Chemerin can play an important biological role in the body by binding to its receptors. First, Chemerin can inhibit the synthesis of cyclic Adenosine Monophosphate (cAMP), activate hormone-sensitive lipase, promote the metabolism of fat cells, and release glycerol and Free Fatty Acids (FFA) [4]. Chemerin was found to increase the level of human preadipocytes and 3T3L1 cells in the process of adipocyte differentiation. Inhibition of chemerin expression by shRNA can inhibit adipocyte differentiation [5]. In addition, chemerin can promote fat decomposition and increase insulin sensitivity by promoting insulin - stimulated glucose transport levels [6].

\section{Chemerin promotes inflammation}

The study found that chemerin can promote the migration and recruitment of dendritic cells and macrophages [7], participate in tissue immune and inflammatory responses. Chemerin is generally generated in the early stage of inflammation [8]. Chemerin binding to its receptor CMKLR1, can activate the nuclear factor- $\kappa \mathrm{B}$ and Mitogen-Activated Protein Kinase (MAPK) pathways in monocytes, macrophages and immature dendritic cells [9], which play a role in the inflammatory response. Other studies have also confirmed that chemerin is closely related to inflammatory markers, such as TNF- $\alpha$, and Il-6 $[10,11]$. Serum chemerin level is positively correlated with C-Reactive Protein (CRP) $[12,13]$ that is a marker of inflammation. In addition, the expression of CMKLR1 in vascular endothelial cells was regulated by inflammatory cytokines [14]. These results suggest that chemerin and its receptor CMKLR1 system may play a role in the inflammatory state of vascular endothelial cells.

\section{Chemerin is involved in oxidative stress}

In human vascular endothelial cells, chemerin can increase the production of mitochondrial ROS [15]. The increase of ROS can increase the level of oxidative stress, thus aggravating oxidative damage. The generation of chemerin-related ROS can be reduced by using shRNA to knock out chemerin receptors or by using antioxidative therapy targeting mitochondria [15]. Another study found that chemerin is closely related to 8-isoprotaglandim F2 (8-iso-pgf2), which is an indicator of oxidative stress process [16]. Chemerin can improve oxidative stress response [9] and is negatively correlated with HDL-linked paraoxonase-1 enzyme in the body [17]. Thus, chemerin plays an important role in oxidative stress.

\section{Chemerin promotes neovascularization}

Recent studies have also found that chemerin is involved in the formation of neovascularization [18]. Chemerin and its receptor CMKLR1 system under the condition of the inflammation can promote cell migration [7]. Chemerin can induce the formation of neovascularization in human endothelial cells and promote the endothelial cells migration and tube formation and activate endothelial cells gelatinases (MMP - $2 /$ - 9) and phosphatidyl inositol 3 kinase (PI3K)/AKT and MAPK pathways, these are the key mechanism of angiogenesis and cell survival [19]. Chemerin can promote angiogenesis through inflammatory pathways. The early stage of inflammatory can stimulate the mobilization and homing of endothelial progenitor cells, proliferate and differentiate into mature endothelial cells, which is helpful to repair the injury induced by the inflammatory and promote

${ }^{\star}$ Correspondence to: Junhui Du, Department of Ophthalmology, Xi'an Ninth Hospital Affiliated to Medical College of Xi'an Jiaotong University, Xi'an 710054, Shaanxi Province, China, E-mail: djh79918@163.com

Key words: diabetic retinopathy, retinal neovascularization, chemerin

Received: December 14, 2018; Accepted: December 26, 2018; Published: January 01, 2019 
the formation of neovascularization [20]. Matrix Metalloproteinase - 2 (MMP-2) and Matrix Metalloproteinases-9 (MMP-9) play an important role in angiogenesis, which can degradate collagen type IV extracellular matrix, prompting the extracellular matrix remodeling and cell migration [21,22]. Chemerin can induce the MMP - 2 and MMP - 9, and then promote vascular endothelial cell regeneration [23]. Chemerin can promote angiogenesis in a dose-dependent manner [18]. Therefore, chemerin may promote neovascularization in many ways.

In previous studies, it was found that the expression of chemerin was increased in the serum of patients with diabetic retinopathy, especially in the patients with PDR [2]. Some scholars also found that the expression of chemerin in the intraocular fluid of PDR patients was significantly increased [3]. And chemerin plays a key role in angiogenesis in vitro [24], it can significantly promote the proliferation, migration and tube formation of retinal endothelial cells. Therefore, chemerin may play an important role in the pathogenesis of diabetic retinopathy by promoting inflammatory, oxidative stress and angiogenesis.

\section{References}

1. Al-Kharashi AS (2018) Role of oxidative stress, inflammation, hypoxia and angiogenesis in the development of diabetic retinopathy. Saudi J Ophthalmol. [Crossref]

2. Du J, Li R, Xu L, Ma R, Liu J (2016) Increased Serum Chemerin Levels in Diabetic Retinopathy of Type 2 Diabetic Patients. Curr Eye Res 41: 114-120. [Crossref]

3. Li J, Hu WC, Song H, Lin JN, Tang X (2016) Increased Vitreous Chemerin Levels Are Associated with Proliferative Diabetic Retinopathy. Ophthalmologica 236: 61-66. [Crossref]

4. Roh SG, Song SH, Choi KC, Katoh K, Wittamer V, et al. (2007) Chemerin--a new adipokine that modulates adipogenesis via its own receptor. Biochem Biophys Res Commun 362: 1013-1018. [Crossref]

5. Goralski KB, Mccarthy TC, Hanniman EA, Zabel BA, Butcher EC, et al. (2007) Chemerin, a novel adipokine that regulates adipogenesis and adipocyte metabolism. $J$ Biol Chem 282: 28175-28188. [Crossref]

6. Takahashi M, Takahashi Y, Takahashi K, Zolotaryov FN, Hong KS, et al. (2008) Chemerin enhances insulin signaling and potentiates insulin-stimulated glucose uptake in 3T3-L1 adipocytes. FEBS Lett 582: 573-578. [Crossref]

7. Parolini S, Santoro A, Marcenaro E, Luini W, Massardi L, et al. (2007) The role of chemerin in the colocalization of NK and dendritic cell subsets into inflamed tissues. Blood 109: 3625-3632. [Crossref]

8. Wittamer V, Bondue B, Guillabert A, Vassart G, Parmentier M, et al. (2005) Neutrophilmediated maturation of chemerin: a link between innate and adaptive immunity. $J$ Immunol 175: 487-493. [Crossref]

9. Bozaoglu K, Bolton K, McMillan J, Zimmet P, Jowett J, et al. (2007) Chemerin is a novel adipokine associated with obesity and metabolic syndrome. Endocrinology 148: 4687-4694. [Crossref]
10. Yamamoto T, Qureshi AR, Anderstam B, Heimbürger O, Bárány P, et al. (2010) Clinical importance of an elevated circulating chemerin level in incident dialysis patients. Nephrol Dial Transplant 25: 4017-4023. [Crossref]

11. Lehrke M, Becker A, Greif M, Stark R, Laubender RP, et al. (2009) Chemerin is associated with markers of inflammation and components of the metabolic syndrome but does not predict coronary atherosclerosis. Eur J Endocrinol 161: 339-344. [Crossref]

12. Hu W, Feng P (2011) Elevated serum chemerin concentrations are associated with renal dysfunction in type 2 diabetic patients. Diabetes Res Clin Pract 91: 159-163. [Crossref]

13. Weigert J, Neumeier M, Wanninger J, Filarsky M, Bauer S, et al. (2010) Systemic chemerin is related to inflammation rather than obesity in type 2 diabetes. Clin Endocrinol (Oxf) 72: 342-348. [Crossref]

14. Yamawaki H (2011) Vascular effects of novel adipocytokines: focus on vascular contractility and inflammatory responses. J Biol Pharm Bull 34: 307-310. [Crossref]

15. Shen W, Tian C, Chen H, Yang Y, Zhu D, et al. (2013) Oxidative stress mediates chemerin-induced autophagy in endothelial cells. Free Radic Biol Med 55: 73-82. [Crossref]

16. Yu S, Zhang Y, Li MZ, Xu H, Wang Q, et al. (2012) Chemerin and apelin are positively correlated with inflammation in obese type 2 diabetic patients. Chin Med J (Engl) 125 3440-3444. [Crossref]

17. Fulop P, Seres I, Lorincz H, Harangi M, Somodi S, (2014) Association of chemerin with oxidative stress, inflammation and classical adipokines in non-diabetic obese patients. $J$ Cell Mol Med 18: 1313-1320. [Crossref]

18. Bozaoglu K, Curran JE, Stocker CJ, Zaibi MS, Segal D, et al. (2010) Chemerin, a novel adipokine in the regulation of angiogenesis. J Clin Endocrinol Metab 95: 2476-2485. [Crossref]

19. Kaur J, Adya R, Tan B K, Chen J, Randeva HS (2010) Identification of chemerin receptor (ChemR23) in human endothelial cells: chemerin-induced endothelial angiogenesis. Biochem Biophys Res Commun 391: 1762-1768. [Crossref]

20. Lin CP, Lin FY, Huang PH, Chen YL, Chen WC, et al. (2013) Endothelial progenitor cell dysfunction in cardiovascular diseases: role of reactive oxygen species and inflammation. Biomed Res Int 845037. [Crossref]

21. Santos JM, Tewari S, Lin JY, Kowluru RA (2013) Interrelationship between activation of matrix metalloproteinases and mitochondrial dysfunction in the development of diabetic retinopathy. Biochem Biophys Res Commun 438: 760-764. [Crossref]

22. Hughes B G, Fan X, Cho W J, Schulz R (2014) MMP-2 is localized to the mitochondriaassociated membrane of the heart. Am J Physiol Heart Circ Physiol 306: H764-H770. [Crossref]

23. Kaur J, Adya R, Tan B K, Chen J, Randeva HS (2010) Identification of chemerin receptor (ChemR23) in human endothelial cells: chemerin-induced endothelial angiogenesis. Biochem Biophys Res Commun 391: 1762-1768. [Crossref]

24. Du JH, Li R, Yang L (2016) The role of autophagy in chemerin-induced angiogenesis of RF/6A cells. Int J Clin Exp Med 9: 17802-17811.

Copyright: (C2019 Liu M. This is an open-access article distributed under the terms of the Creative Commons Attribution License, which permits unrestricted use, distribution, and reproduction in any medium, provided the original author and source are credited. 